\title{
ENTRE LA IGNORANCIA Y EL DESPRECIO: LAS RELACIONES ENTRE LENGUAJE, POLÍTICA Y EDUCACIÓN EN LA ESTRUCTURACIÓN DEL MITO DE LA ATENAS SURAMERICANA EN EL SIGLO XIX
}

\section{Resumen}

El artículo busca motivar la discusión sobre el mito cultural de la Atenas Suramericana y su estrecha relación con procesos de configuración de relaciones de obediencia / desobediencia, así como con la construcción de identidades y diferentes sentidos de pertenencia que se presentaron en Bogotá en el siglo XIX a través del uso correcto del lenguaje. Metodología: Ante la carencia de estudios sobre el mito cultural, el artículo plantea una articulación de la historia cultural con algunos conceptos de la teoría bourdiviana como el concepto de capital cultural para hacer evidentes unas prácticas culturales inscritas en relaciones de fuerza y en las estructuraciones económicas, sociales y culturales. Por medio del análisis de las prácticas culturales se logró suplir las escasas referencias del Mito de la Atenas Suramericana en las fuentes documentales analizadas como la prensa de la época, revistas, crónicas y relatos de viajeros. Originalidad: Plantea una relación cercana entre lenguaje, política y educación en la estructuración del Mito de la Atenas Suramericana. Conclusiones La importancia de los mitos culturales, en especial el mito de la Atenas suramericana explica el inacabado proyecto cultural colombiano, desde la exclusión, la desigualdad, la burla, las apariencias y los estrechos caminos hacia la política. El uso correcto del lenguaje fue un mecanismo cultural 
que más que funcionar para la democratización de la palabra, se convirtió en un recurso simbólico para la exclusión y el encumbramiento de una identidad dominante.

Palabras clave: Historia cultural, Mito cultural, uso del lenguaje, capital cultural, práctica cultural

\section{Abstract}

Objective / context: the article seeks to motivate the discussion on the cultural myth of South American Athens and its close relationship with processes of configuration of obedience / disobedience relationships, as well as with the construction of identities and different senses of belonging that were presented in Bogotá. in the 19th century through the correct use of language. Methodology: In the absence of studies on cultural myth, the article proposes an articulation of cultural history with some concepts of the bourdivian theory such as the concept of cultural capital to make evident cultural practices inscribed in relations of force and in economic structures, social and cultural. Through the analysis of cultural practices, it was possible to supply the scarce references of the Myth of the South American Athens in the documentary sources analyzed such as the press of the time, magazines, chronicles and stories of travelers. Originality: It raises a close relationship between language, politics and education in structuring the Myth of the South American Athens. Conclusions The importance of cultural myths, especially the myth of South American Athens explains the unfinished Colombian cultural project, from exclusion, inequality, mockery, appearances, 
and the narrow paths to politics. The correct use of language was a cultural mechanism that, more than working for the democratization of the word, became a symbolic resource for the exclusion and elevation of a dominant identity.

Key words: Cultural history, Cultural myth, use of language, cultural capital, cultural practice

\section{Introducción}

El uso correcto del lenguaje como práctica cultural y política, propició en la Bogotá del siglo XIX, los más variados sentimientos como el honor, la amistad, el desprecio y la humillación. Saber hablar y escribir bajo las formas correctas del idioma, además de constituirse en una práctica cultural excluyente, se vinculó con algunos asuntos de moral y modal que buscaron fortalecer el hispanismo, las buenas costumbres y la conexión identitaria con España. Estos elementos emocionales de la cultura como la valoración y la descalificación, el desprecio y la exaltación y de otro lado, la humillación y el reconocimiento, se convirtieron en mecanismos de diferenciación social entre quienes eran capaces de mantener una pulcritud lingüística y un uso correcto del lenguaje y quienes no lo lograban. Este derecho de pertenencia adquirido en la defensa del lenguaje visto como objeto sagrado de la cultura y la exaltación del letrado como ser sobrenatural, permitió la estructuración de uno de los mitos culturales más complejos de Sur América: el mito de la Atenas de Suramérica. 
Ahora bien, en la relación entre lenguaje, escritura y política se hace evidente el desprecio por el iletrado y el papel preponderante de una educación clásica reafirmada sobre las buenas maneras y el culto al lenguaje. La exaltación de la ignorancia y la ausencia de este capital cultural fue objeto de las más variadas burlas en la sociedad bogotana del siglo XIX. El uso correcto del lenguaje aunque podía ser adquirido mediante una rigurosa vida académica por vía de la lectura de los clásicos y las gramáticas, era más que evidente que el analfabetismo, la desigualdad y la jerarquización de la sociedad no permitían una democratización de la palabra. Bajo estas condiciones materiales y simbólicas, se estructuró el mito de la Atenas Suramericana.

\section{Los estudios sobre el mito y el papel de las academias}

En Colombia, los estudios desarrollados desde una perspectiva histórica sobre el uso del lenguaje han propuesto una relación directa con la política ${ }^{1}$. Estos estudios sostienen además que la relación entre lenguaje y política se vinculó con el conocimiento de galicismos, de provincialismos, el manejo del latín y sobre todo, con las correcciones idiomáticas, que por lo general se utilizaban para el ataque y la defensa en política. La tendencia generalizada de suponer que la excelencia en las letras es un reflejo del grado de civilización de un pueblo, y que hay una conexión directa entre las virtudes de la población y las obras de sus elites

\footnotetext{
1 Malcom, Deas. "Miguel Antonio Caro y sus amigos: gramática y poder en Colombia". En Del poder y la gramática y otros ensayos sobre historia política y literatura colombiana. Bogotá: Tercer mundo editores, 1993, 27-61, Williams, Raymond. Novela y poder en Colombia. Bogotá: Tercer Mundo editores, 1991. Fabio Zambrano. "De la Atenas suramericana a la Bogotá moderna. La construcción de la cultura ciudadana en Bogotá". Revista de estudios sociales, $n^{\circ} 11$ (2002): 9-16. Fabián, Llano. Caro, Cuervo y la resistencia lingüística. Construcción de la identidad ciudadana, desde el uso de la lengua. Bogotá (1880-1950). Bogotá: Editorial Universidad La Gran Colombia, 2012.
} 
letradas, les ha permitido a los colombianos durante más de un siglo ufanarse de la alta cultura que profesaban sus prohombres. Bogotá todavía se precia -aunque cada vez más tímidamente- de haber sido considerada la Atenas sudamericana ${ }^{2}$

Lo anterior se puede explicar, de acuerdo en esta relación entre idioma y nación donde se fundamentó un gusto nacional basado en la convicción, que la cultura de los hombres cultos era la de todos los colombianos. Este binomio entre idioma y nación se unió basándose en el antecedente de la conquista española hasta tal punto que se terminó por cambiar la celebración de Bogotá el 6 de agosto de cada año por la fiesta del idioma bajo un proyecto civilizador nacional. Idioma y nación se hicieron uno en términos de futuro al fijar su posibilidad, no en la libertad sino en el orden mediante academias y sus sacerdotes y bajo las normas y los presidentes gramáticos. De esta manera, el idioma y la nación en el habla bogotana se convirtió en el proyecto civilizador de sociedades cerradas bajo un centralismo político a excepción del gobierno de Santiago Pérez³ . Además como sostiene Rincón (2014) esta realidad cultural estuvo caracterizada por una vinculación a la cosmología cristiana, unos procesos coartados e incompletos para formar una nación moderna y por una sincronía cultural e intelectual de los grupos dominantes frente al proyecto de la modernidad y el hispano centrismo, que valga decir, utilizaron estrategias reactivas que atravesaron el afán de

\footnotetext{
${ }^{2}$ Erna Von der Walde Uribe, “. Limpia, fija y da esplendor: el letrado y la letra en Colombia a finales del siglo XIX". Revista Iberoamericana volumen. 63, Siglo XIX, fundación y fronteras de la ciudadanía, editado por Susana Rotker, 178-179, Enero-Junio,; 71-83.

${ }^{3}$ Germán, Mejía. "El idioma de la nación, la experiencia decimonónica colombiana". Ínsula revista de letras y ciencias humanas, ${ }^{\circ} 762$ (2010): 16-20
} 
modernidad con el mito de la Atenas suramericana que prosperó bajo la sombra de un mito patriótico originario bajo resistencias culturales y héroes culturales como Rafael Pombo.

Son muchas las discusiones sobre el origen del mito ${ }^{4}$ El apelativo de Atenas suramericana, Atenas del sur o "la ciudad del águila negra" hacen referencia a diferentes nominaciones realizadas para representar la cultura literaria de Bogotá en el siglo XIX. Aunque el origen del mote se le endilga al geógrafo francés Eliceo Reclus, también aparecen otras versiones. Una referencia distinta apareció en Madrid, España entre 1893 y 1895, con la publicación de antología de poetas hispanoamericanos por Marcelino Menéndez Pelayo, quien caracterizó la cultura literaria de Santa fé de Bogotá como la Atenas de la América del sur (Montenegro, 2003). Aunque existen otras versiones que indican que las formas que adquiere el apelativo no parten directamente de Reclus, sino desde un auto reconocimiento con el mundo literario español, se instaura este mote bajo el contexto de un país en crisis y consagrado al sangrante corazón de Jesús (Rincón, 2008) ${ }^{5}$.

De acuerdo con Zambrano (2002) la Atenas suramericana era un espejismo vivido en el atrio de la catedral donde una comunidad homogénea buscó articular un proyecto civilizador que

\footnotetext{
4 Para el caso colombiano los planteamientos de Zambrano (1994) fortalecen la importancia de los mitos en la constitución de una identidad nacional. De acuerdo con el autor, la contaminación de un imaginario político atravesado por un discurso liberal igualitario y la práctica de una sociedad conservadora intento resolver el conflicto de una sociedad fragmentada y conflictiva a través de mitos tradicionales que buscaba un reconocimiento e identificación común." (p 66).

${ }^{5}$ De acuerdo con Rincón (2008) Eliseo Reclus hacia 1860 fue redactor de guías de viaje luego de recibir la influencia de Karl Ritter, geógrafo que enseñaba en el ámbito universitario. Su conexión con el país, estuvo relacionada para la misma época con una exploración y explotación en inmediaciones de la sierra Nevada de Santa Martha. En un artículo publicado en Revue de Deux, relaciona la literatura del continente colombino con el Paris moderno. En una suerte de evocación a partir de lo clásico Reclus sostuvo que a mitades del siglo XIX había dos Atenas en Suramérica: Buenos Aires y Bogotá (p18).
} 
se impusiera sobre los otros, es decir frente a los guaches y los barbaros que ignoraban el griego y pasaban las más elementales reglas de cortesía y comportamiento. En el altozano descubría hombres de distintas condiciones políticas como José María Samper (a quien consideraba liberal acérrimo). Que en algunas ocasiones se conectaba con los pobres mediante anécdotas como la Guaricha (p. 474) y la partida de Tejo de Moratín. A pesar que, en algunos momentos, esta comunidad homogénea tuviera algunas diferencias políticas (sangrienta historia política) dos hechos incontrovertibles mantuvieron su homogeneidad: el espíritu caballeresco y el lenguaje esmerado. En esta comunidad existía una camaradería entre los miembros del mosaico basada en una homogeneidad de trato y en la vigilancia de unos miembros sobre otros para conformar una utopía letrada y una ciudad ideal.

Frente a un ambiente cultural, que valga decir, se desarrolló principalmente al interior de las viviendas, en algunas tiendas de la calle del comercio, hoy carrera séptima y el altozano de la catedral, también era evidente un ritmo urbano lento con escasas posibilidades de lo público, un escaso mobiliario urbano, una sociedad jerarquizada y una dinámica económica concentradas en las tiendas y en los almacenes. Las condiciones materiales de un paisaje urbano en ciernes y una sociedad desigual como la bogotana permiten hacer evidentes las contradicciones sociales que se presentaron durante todo el siglo XIX (Serna, 2001, Zambrano, 2002, Mejía, 2008, Chavarro \& Llano, 2010).

Bajo una misma topografía colonial, la vieja ciudad santafereña mantuvo sus límites casi intactos, con San Diego al norte, San Cristóbal al sur y San Victorino al occidente, mientras permanecía replegada en el pie de los cerros orientales. Las tiendas que estaban sobre las 
calzadas eran descritas como antros infectos sin luz, la ciudad con tinte colonial permanecía a oscuras, las chicherías dominaban el paisaje urbano, aun en los sectores exclusivos, al no existir alcantarillado, eran evidentes los caños olorosos que atravesaban las principales vías y por último la industria era casi nula. Con estas descripciones tomadas de los relatos de viajeros se sostiene que la invención de una cultura ateniense en relación y la formación de una identidad bogotana, fue perpetrada por una elite letrada que legitimó unas formas concretas de cultura. La apropiación del mito fue utilizada como un mecanismo de segregación social que repercutió en la interacción cotidiana como en la organización espacial que hasta finales del siglo XIX se mantenía incólume ${ }^{6}$.

En efecto, los epítetos del águila negra o Atenas suramericana representaban la realidad de unos pocos. De acuerdo con Jaramillo (1998) estos “espíritus selectos” mencionaban en sus obras a esa ciudad de los pobres e ignorantes transformándolos en ocasiones en seres dóciles, limpios e higiénicos, pero otro modo de visibilizarlos se dio por medio de cuadros de costumbres donde se representaba la miseria y los tipos sociales como las aguadoras, reclutas, y la idealización de la figura del guache. Estos modos entusiastas de representación sobre una modernidad cultural incluía la exaltación de los valores hispanos y culturales sobre las representaciones asociadas a la transformación de la ciudad desde sus espacios físicos. Así proliferaron las formas de representación de lo moderno caracterizado por el apego a las

\footnotetext{
${ }^{6}$ Solo hasta finales del siglo XIX se hizo evidente este cambio de un sistema colonial a la lógica del lucro y la renta propios de un sistema capitalista. Esto se logró gracias a una transformación de la lógica económica que pasó de la explotación de la tierra de los grandes terratenientes a nuevas estructuraciones económicas que quebraron el modelo económico colonial. De este modo, un deseo de modernidad estuvo presente en la elite del país alrededor de un proyecto de ciudad muy al estilo de algunas ciudades europeas como Paris y Londres y el fuerte paradigma estadunidense, que bajo los grandes rascacielos de Nueva York marcaron una tendencia en la arquitectura y en la difusión de un estilo de vida cosmopolita (Serna, 2001; Pérgolis, 2013)
} 
formas clásicas y tradicionales representadas en la idea de Bogotá como la Atenas de América del sur (Llano, 2012).

Un antecedente importante de esta tradición lingüística se encuentra también en la construcción literaria de la nación. En este sentido, Vallejo (2010) resalta el papel protagónico del Papel Periódico Ilustrado bajo el liderazgo de Alberto Urdaneta. Aunque el este periódico ilustrado intentó ser neutral para consolidar un proyecto moderno de nación bajo la formación de una opinión pública, lo que en realidad postuló fue una cercanía de los géneros literarios asociadas a la pulcritud del lenguaje.

Otra preocupación era formar lectores a través de la educación y la divulgación de revistas. El mosaico fue la escuela de formación de lecturas más significativa del siglo XIX. A mediados del siglo XIX ninguna persona medianamente instruida negaba la importancia de la escritura en la gesta independentista. Lo que posibilitó la consolidación de esta idea, fue la producción literaria y el aumento de imperantes, editoriales y periódicos, esfuerzo mayoritariamente privado, pero también estatal (Mejía, 2010 p. 13).

Desde estas consideraciones, la representación de la Atenas suramericana estuvo ligada al secreto de una comunidad imaginada letrada, que al contrario de la producción cultural europea, silenció las emociones de la literatura. En la parroquial Bogotá se silenciaban las emociones y los instintos más humanos que podían ser representados literariamente. En la literatura hispanista (predominante) solo se encuentran algunas referencias al tema de la 
prostitución como el caso de José María Vargas Villa con sus novelas María Magdalena (1919) y Salome (1920) (Peralta, 2002).

De acuerdo con Raymond L. Williams (1991) la elite colombiana privilegió el ensayo y la poesía como géneros ideales. Los escritores de novelas como María y la vorágine habían perseguido ser reconocidos como poetas antes que como novelistas. Aunque caben destacar que los novelistas generalmente han sido liberales y los críticos conservadores, casi siempre estos personajes se dedicaron a la política. Por ejemplo, los conservadores creían que los hombres de letras debían formarse en la escuela pública. Cabe destacar que, para esta época, el salón y la escuela fueron escenarios de enfrentamientos entre los partidos políticos para la moralización de la masa analfabeta. Por ejemplo, en la arcadia como en la utopía, el indígena necesita ser civilizado como en las novelas ingermira o la hija de Calamar de Juan José Nieto y el mudo Eladio Vergara. La novela más notable de esta época fue Manuela, aunque es necesario advertir que Eugenio Díaz era un conservador que no se ajustó al modelo de letras conservador, por eso se mantuvo apartado del diario quehacer político. También, desde el punto de vista del dialogo político y la militancia, podrían considerarse marginales José Caicedo Rojas y José David Guarín (conocidos por sus cuadros de costumbres) (Williams, 1991).

Al respecto, Acosta (2011) se centra en dos usos característicos de la producción literaria de este periodo de tiempo: los cuadros de costumbres y la novela. Para el primero de los casos, esta estrategia de representación de los tipos y las costumbres de las clases sociales permitía un cierto tipo de orden donde se establecían las diferencias sociales, pero no se denunciaban 
las injusticias y las inequidades, lejos de tener una connotación de crítica social, los cuadros de costumbres mostraron a través de la contrastación, la construcción de un mundo expuesto a los ojos de los demás bajo el chiste.

Finalmente, esta tradición lingüística encarnada por grandes filólogos, gramáticos y lingüistas estuvo ligada a las pretensiones de constituir una identidad nacional de carácter homogeneizante que reclamaba el uso correcto del idioma, como parte fundamental para participar en la política, en la vida pública y en el ejercicio de las letras. En efecto, esta comunidad conformada por filólogos, gramáticos, poetas, escritores y novelistas promovieron a través del mito, no solo vínculos de pertenencia cultural y político alrededor del uso correcto del lenguaje, sino que además, bajo el proyecto político y cultural de la regeneración, buscaron la promoción de una Bogotá culta. Cabe resaltar que más que lograr una libre circulación de la palabra, una construcción de opinión pública fuerte y una democratización de la cultura, los letrados en el poder, reivindicaron el uso correcto del lenguaje como un capital cultural de resistencia para hacerle frente a los cambios económicos y urbanos de una naciente burguesía en la ciudad.

Como práctica lingüística que se desarrolló en medio de las transformaciones económicas, sociales y culturales de la ciudad no solamente buscó la proyección de una imagen erudita de la ciudad conocida como la Atenas Suramericana para hacerle frente a la naciente burguesía bogotana, sino que por medio de la censura, el insulto, la descalificación y la clasificación social, los letrados intentaron transgredir estos cambios mediante el anacronismo de criterios coloniales como la limpieza de sangre, el orgullo de linaje, y el prejuicio social, convirtiendo 
el uso correcto del lenguaje en un mecanismo para impedir el cambio y suprimir otras identidades culturales que intentaban posicionarse en la ciudad (Serna, 2001, Llano, 2012).

\section{Las academias y la legitimidad lingüística}

Esta práctica lingüística no habría podido ser tan eficaz sin el agenciamiento de las Academias. Tal como refiere Mejía (2010) los antecedentes de una Academia de la Lengua se puede rastrear en el periódico la Miscelánea de 1825 donde Francisco de Paula Santander solicitaba la creación de una Academia Americana. Para finales de 1870 se conformaba en el país un grupo con un interés expresivo similar, el cual convergía en la custodia del idioma. Esta pertenencia a este grupo tan selecto, se empieza a consolidar con el viaje de Vergara y Vergara a España para hablar con el director de la Academia de Madrid, Don Mariano Roca de Togores. En este viaje Vergara y Vergara consiguió la firma del acuerdo del 24 de noviembre de 1870, donde se autorizaba la creación de academias correspondientes en los países hispanoamericanos: La Academia Española de Madrid estimula la creación de entidades similares en América, que llama correspondientes": así se organizaron la Academia Colombiana de la Lengua (1871), la Mexicana (1875), la Ecuatoriana (1875), la Venezolana (1883), la Peruana, la Chilena y la Argentina y luego otras. En los primeros tiempos fueron activas y dieron luz a revistas o anales con trabajos valiosos, especialmente la de Colombia y la de México; colaboraron en el Diccionario de la Lengua Castellana (Ureña, 2001, p100) Habiendo regresado a Bogotá el señor Vergara y Vergara, se reunió en su casa el 10 de mayo de 1871, con los señores don Miguel Antonio Caro y don José Manuel Marroquín, en junta 
preparatoria, para echar los fundamentos de la Academia Colombiana de la Lengua" (Guzmán: 1993, p14)

Luego de esta reunión y frente a las amenazas que suponían la circulación de diferentes neologismos y modas lingüísticas extranjeras, esta identidad dominante se dio a la tarea de empezar a producir y reproducir gramáticas, libros y librillos que tenían por objeto regular el idioma y enaltecer una conexión directa con la identidad española. Esto permitió poner las bases de una historia primordial y hacer visibles unos personajes autorizados para hablar en público. De este modo, una vez se logró establecer la Academia, fue necesario entonces pensar en el tipo de personalidades que iban a conformarla: gramáticos, filólogos, poetas, novelistas y todo hombre de letras que velará por la pureza del lenguaje. Estos efectos en la vida cotidiana estructuran unas posiciones legitimadas para hablar bien y otras que son excluidas por no hacerlo desde las formas del buen decir como atributo de distinción (Bourdieu, 2001).

Aquí se hace relevante mencionar que aunque el establecimiento de sociedades, academias y fundaciones fuera otra de las estrategias adoptadas para que las clases altas impusieran su estilo de vida, se requerían de otras estrategias culturales para lograr imponer esta creencia en la ciudad y la ciudadanía. En estos términos se hizo necesario privilegiar la eficacia de la lengua como recurso simbólico. El uso del más selecto castellano no solo atrajo a eruditos preocupados por el cultivo de la lengua, sino a letrados interesados en hacer historia. En esta medida, las formas legítimas de hacer historia se vinculó con la erudición y la pulcritud lingüística por medio de la Academia Colombiana de Historia. Las biografías, el estilo y la 
pulcritud lingüística fueron los elementos fundamentales con los cuales se escribió la historia por lo menos hasta la mitad del siglo XX (Llano, 2011).

De otro lado, ante la ausencia de un periodismo fuerte, la producción cultural estuvo más bien reducida a unos pocos letrados quienes establecieron y estructuraron un capital cultural asociado al uso correcto del lenguaje. Por ejemplo, esto se hizo evidente desde el oficio del periodismo, donde aparecían los ataques políticos bajo una pulcritud lingüística que muchas veces se constituían en ensayos y en estudios literarios ${ }^{7}$

La prensa diaria es un medio formativo de primer orden en todo país nuevo. Por entonces aparecían en Bogotá nada menos que de veinte a treinta publicaciones periódicas, tanto políticas como de contenido científico, pero sólo una salía diariamente. Muchos de los periódicos políticos tenían una brevísima existencia, desapareciendo ya al segundo o tercer número. Como los periódicos no podían vivir del mismo modo que los nuestros, o sea a base de noticias del día y telegramas, concentraban su energía en los artículos de fondo, en estudios literarios, traducciones, desahogos líricos y crónicas locales (Rothlisberger p1896)

En efecto, los periódicos que más duraron, lo hicieron por espacio de cinco años y fueron el Neogranadino y el Tiempo. Además de esto, las producciones para este tiempo apenas

\footnotetext{
${ }^{7}$ No suma treinta nombres la lista de los grandes ensayistas colombianos en el Siglo Diecinueve. José Eusebio Caro, José María Torres Caicedo, Ulpiano González, Joaquín Posada Gutiérrez, José María Vergara y Vergara, José Antonio de Plaza, José María Quijano Otero, Manuel Ancizar, Felipe Pérez, Salvador Camacho Roldán, Manuel Uribe Ángel, Manuel María Madiedo, Miguel y José María Samper, Soledad Acosta de Samper, Ezequiel Uricoechea, Rufino José Cuervo, Florentino Vezga, Cerbeleón Pinzón, Miguel Antonio Caro, Rafael Núñez, Carlos Cuervo Márquez, Isidoro Laverde Amaya, Federico Cornelio Aguilar, Ángel Cuervo, César C. Guzmán, José Manuel Groot, Medardo Rivas, Eugenio Ortega, Vicente Restrepo, entre no muchos otros intelectuales que legaron un importante trabajo cualitativo de ensayos sobre diversas materias (Santos:2007p3)
} 
comenzaban a incrementarse. Si bien es cierto que entre las décadas de 1830 (89) a 1870 (114) el número de publicaciones se incrementó aproximadamente un $22 \%$ no resultó un aumento en las publicaciones definitivo. Esto demuestra que la empresa literaria apenas se encontraba en ciernes y solo hasta la década del noventa (1890- (293)) se presenta en el país un aumento significativo de la producción cultural, duplicando la producción de la época anterior (Villalobos: 1994)

Sin embargo, el papel periódico ilustrado fue una excepción sobre la producción cultural de la época, que como ya se ha mencionado tenía por característica tener poca continuidad. En efecto, donde mejor se logra comprender el alcance de la pulcritud lingüística en una publicación prácticamente apolítica fue el proyecto editorial denominado papel periódico ilustrado que apareció a finales del siglo XIX. El director de esta publicación fue el bogotano Alberto Urdaneta Urdaneta, junto con sus colaboradores el grabador español Antonio Rodríguez y Manuel Briceño. Tuvo en las ilustraciones un componente determinante que abrió paso a los magazines culturales para tomar distancia del periodismo de filiación política $^{8}$. Tal como sostiene Vallejo (2010) los textos publicados, literarios, periodísticos o informativos no eran plataformas de discusiones políticas o de agresiones partidistas, esta característica apolítica del papel periódico ilustrado, donde primaba la pulcritud lingüística y la remuneración de los artículos publicados, tomó la forma de un álbum nacional de la

8 Este cambio en el direccionamiento de las producciones culturales hacia lo apolítico resulta determinante si se tiene en cuenta que la producción de ensayos para el periodo de 1850 y 1865 fue la más destacada, ya que, los objetivos de la elite bogotana, estaban precisamente orientados a consolidar las empresas ideológicas que los intelectuales proyectaron en la utopía liberal y la arcadia helena católica. En este sentido, la oligarquía colombiana no producía novelas se creía que las novelas y el género novelístico, no contribuían significativamente a la empresa ideológica, a la política de la clase alta o a la elite intelectual. El ensayo político, por el contrario, tenía un impacto mucho más pronunciado (Llano 2013 citando a Raymond: 1991p. 44) 
independencia para mostrarle al mundo lo mejor de los paisajes nacionales y sus talentosos artistas.

Finalmente, el papel de las academias y las producciones culturales en la legitimación del uso correcto del lenguaje como atributo distintivo, requirió además de la institucionalización de esta práctica lingüística desde una educación clásica y confesional. El papel de la educación en la formación de los letrados fue fundamental para la estructuración del mito de la Atenas Suramericana en el siglo XIX.

\section{Lenguaje y política: acumulación de capital cultural y talento político.}

Desde la segunda mitad del siglo XIX ya era visible un grupo de comerciantes que se abrieron paso acumulando riqueza y ejerciendo las profesiones liberales. Sin embargo, las empresas de producción y actividades exportadoras relacionadas con las materias primas eran aún incipientes. Las rentas de la clase alta en Bogotá en la primera mitad del siglo XIX frecuentemente alcanzaban a solo unos $\$ 5.000$ anuales por persona, y las personas en Bogotá podían considerarse con los dedos de la mano con un capital mayor de \$100.000. Los ingresos

de la clase media y baja eran correlativamente pequeños. Los pocos elementos de que se componían la clase media, militares y oficiales de bajo rango, pequeños negociantes y artesanos, ganaban entre $\$ 150$ y $\$ 700$ al año. La mayor parte de la obra de mano campesina, así como la gente dedicada al servicio doméstico y los trabajadores no calificados de las ciudades, ganaban entre \$70 y \$ 75 al año" (Safford: 1969: p 89). 
En este sentido, la clase alta bogotana no constituía un grupo social del todo semejante. Ante la imposibilidad de imponer la creencia económica como principio articulador de la coexistencia ciudadana, se hizo más notorio la permanencia de una élite de corte aristocrático, la cual sustentaba su poca riqueza a partir de la herencia de la tierra. En esta dirección, la élite aristocrática se veía en peligro, dada la situación cambiante de su propio grupo social que venía siendo transformado por el comercio de exportación e importación. Otras identidades sobre todo el sector de los artesanos, apostaban por ámbitos como el educativo para el ascenso social.

Cabe advertir que el ingreso al sistema escolar, desde la primaria hasta la universidad, si bien venía creciendo en cobertura, seguía siendo esquivo para estos grupos sociales. Con la poca disposición de planteles educativos y una política de segregación social la educación era propensa más para unas clases sociales que para otras. Por ejemplo, comenzando el siglo XIX, los únicos colegios universitarios que existían en Bogotá eran el seminario San Bartolomé, el Colegio Mayor de Nuestra Señora del Rosario y el Colegio-Universidad de Santo Tomás. El padre Nicolás Cuervo párroco de la parroquia de santa Bárbara en Bogotá se quejó en 1805 ante la real hacienda porque en la capital del virreinato de la Nueva Granada apenas existían dos escuelas públicas. "Una que se debe a la buena memoria y caridad de Antonio González Casadiego, que la dotó con $\$ 400$ anuales [y otra] gratuita [pública] y voluntaria que mantienen [los dominicos] (Gutiérrez: 2000, p42).Además en el Rosario se exigía certificados de nobleza y limpieza de sangre 
lo primero, que todos los colegiales sean legítimos; y aún queremos que sean legítimos sus padres; lo segundo que sus padres no tengan oficios bajos, y mucho menos infames por las leyes del reino; lo tercero que no tengan sangre de la tierra y si la hubieren tenido sus progenitores, hayan salido de manera que puedan tener un hábito de nobleza y no de otra suerte; y lo cuarto que sean personas para el bien público (Constituciones del Colegio Mayor de Nuestra Señora del Rosario. Madrid: Juan Nougués, 1664. En: Guillen: 2002)

De este modo, la universidad colonial neogranadina, representada básicamente por los dos grandes colegios de Santafé de Bogotá: el Colegio del Rosario y el Colegio de San Bartolomé, funcionaron como una forma de defensa contra el mestizaje (Silva: 1993). Evidentemente, la permanencia dentro de este frágil sistema educativo, desde la enseñanza de las primeras letras hasta la educación universitaria, se constituía en requisito indispensable para existir socialmente de forma legítima. Ingresar a estas instituciones educativas era una empresa un tanto dificultosa, incluso para la misma elite santafereña que se vio obligada a abrir algunas instituciones de carácter privado, para cubrir la demanda de necesidades de esta clase social. En este sentido, "A partir de 1827 se crearon algunos colegios, entre los cuales se pueden destacar la Primera Casa de Educación, fundada por José María Triana; la Segunda Casa de Educación; el Colegio del Espíritu Santo, fundado por Lorenzo María Lleras; el Colegio de San Buenaventura, creado por Luís M. Silvestre, y el Colegio de Ricardo Carrasquilla.” (Guillen: 2007)

A los jóvenes se les educaba de acuerdo con la clase social a la cual pertenecían, y las ventajas de haber nacido noble o de ser descendientes de las familias al servicio de la iglesia 
o del gobierno agudizaban aún más las diferencias de clase. [Samper: citado en: Ahern:

1947:11].La educación selectiva tradicional seguía siendo, a pesar de los cambios en la legislación, un componente de suma importancia para el ascenso social. Los habitantes escolarizados en la Nueva Granada correspondían con un sector distinguido de la sociedad, donde se evidenciaba una constante acumulación de educación y manejo de una competencia lingüística que se disponía como un rasgo distintivo que diferenciaba a unos de otros dentro de un espacio social fuertemente jerarquizado.

En este ambiente, prosperó el uso correcto del lenguaje como restitución del modo de vida colonial. En una sociedad estructurada en torno a las apariencias, el uso del lenguaje se proyectó como un rasgo significativo. El valor dado a las letras españolas se constituía, en un tipo de competencia para posicionar a unos hombres de talento. Dentro de este grupo selecto que conformaba la identidad dominante se encontraban algunos personajes dedicados casi por completo al estudio de las letras, ya que, tenían sus condiciones de existencia resueltas por poseer territorios, capitales económicos o pequeñas empresas ${ }^{9}$. Ahora bien, si se tiene en cuenta la desigualdad económica durante la primera mitad del siglo XIX era de esperarse que en la misma dinámica social, se apelara al origen español y con ello, al

\footnotetext{
${ }^{9} \mathrm{Tal}$ es el caso de julio Arboleda, terrateniente caucano dedicado casi por completo a la escritura de poemas y panfletos políticos. Su educación inicial estuvo dirigida por su familia quienes pertenecían a las familias más ilustres del cauca y por supuesto poseían el legado de la educación colonial que básicamente se transmitía a nivel familiar "Julio Arboleda Pombo recibió una educación rica y esmerada. Según Gustavo Arboleda, en su Diccionario biográfico y genealógico del antiguo Departamento del Cauca, Arboleda «adquirió los rudimentos del saber en Popayán, de labios de su abuela materna, Beatriz O'Donnell, y de su preceptor Manuel María Luna. A la edad de once años fue llevado por su padre a Londres, donde siguió su educación al cuidado de un profesor español. Volvió en 1836 a Popayán, por la vía de Cartagena y el Chocó, hizo estudios de jurisprudencia en la Universidad y actuó en la prensa, redactando El Independiente”. [Molano: 2004
} 
dominio de las letras que evidentemente postulaban otra clase de hombres sin riqueza, como personajes de talento dispuestos para la política.

Vargas tejada, por ejemplo carecía de capitales económicos, pero poseía una educación que lo distinguía. "Hoy mismo no puede dejar de sorprendernos la suma erudición literaria que adquirió aquel joven de 27 años de edad. Sus biógrafos nos hacen saber que aprendió en corto tiempo los idiomas inglés, italiano y alemán. También agregan que hizo estudios de griego y hebreo (Laverde: 1963).

Otro ejemplo importante de acumulación de capital cultural, lo encontramos en el caso de Rufino Cuervo que fue elegido vicepresidente de la república para el año 1849. Su padre, D José Antonio Cuervo, que era comerciante, no fue tan prospero en sus negocios y cuando murió, dejo la educación de estos a su hermano D Nicolás que se hizo cargo; sin embargo, D José Antonio, también tenía una preocupación constante por la educación de sus hijos, tal como se muestra en el siguiente fragmento escrito a su esposa:

"Si yo muriere, tú tienes el deber de educarlos: ponlos en una pensión o casa de educación, recomendando con particularidad que aprendan los principios de moral y de religión, la gramática castellana, la aritmética, el dibujo lineal y una buena escritura: cuida después de que aprendan algún arte u oficio, sea cual fuere, con tal de que tengan una ocupación honesta con qué subsistir. (...)"No economices gasto ni sacrificio alguno para educar a nuestros hijos: vende lo más precioso que tengas, porque aun cuando no les dejes bienes de fortuna, ellos tendrán siempre lo bastante con la buena educación."[Cuervo: 1954] 
La buena educación era lo más importante para esta familia y quedará demostrado con las enseñanzas de D Nicolás, tal vez, el familiar que más induce a Rufino Cuervo al acceso del conocimiento. En este sentido su tío es quien le da, en primera instancia lecciones de lengua latina y de virtudes cristianas y luego de esto, lo induce a concederle al conocimiento un valor por encima del dinero, que lo conducirá a posicionar la competencia lingüística como un capital invaluable asociado a la dignidad y por supuesto a la política. Estos capitales simbólicos que provenían directamente del campo del poder, daban cierto prestigio al disponer privilegiadamente de las decisiones políticas, lo que le permitía a pesar de su precariedad económica, participar en el Estado para mantenerse dentro de la élite bogotana. El laureado estaba seguro de ser bien acogido hasta en las casas más distinguidas, y agasajado de todos, entraba de hecho a la aristocracia del talento, superior entonces a la del dinero, y hallaba abierto el camino para una lúcida carrera pública” (Cuervo:1954,p904).

En el siglo XIX en Colombia leer fue una de las formas de participación social y política más importantes. Aunque cabe advertir que los niveles de alfabetización fueron bastante reducidos, fracasaron los diversos proyectos de los grupos radicales de mediados de siglo frente al carácter obligatorio y universal de la educación, y además, los avances de los grupos de artesanos para igualar su educación con la de la elite quedaron truncados. Ser lector hacía parte de la definición de una posición social privilegiada. La lectura, ubicada generalmente distante de los mundos campesinos, tuvo su eje en las ciudades que hicieron alarde del poder que les asignaba su carácter letrado, generando así un nuevo elemento de diferenciación (Acosta: 2007). Además del escaso apoyo gubernamental al sostenimiento de las escuelas 
públicas, la educación de los niños pertenecientes a los sectores bajos de la sociedad, era encargada a personas con escasa formación, que muchas veces emprendían la docencia solo para tener un precario ingreso que apenas les permitía subsistir [Ahern: 1947: 10].

En suma, los habitantes escolarizados en la Nueva Granada, correspondían solamente a un sector distinguido de la sociedad, quienes por supuesto, gracias a la carencia de formación de otros sectores, evidenciaban una constante acumulación de educación soportada en gran medida en la posesión de títulos nobiliariarios y de pureza de raza. En este sentido, la competencia lingüística se disponía como un rasgo distintivo para diferenciar unas clases sociales sobre otras.

\section{Escritura política y proyecto cultural.}

Las diferencias y los intereses políticos también se comenzaban a poner de manifiesto dentro de la elite. Como muestra de lo anterior se muestra un fragmento de la carta que envió José Hilario López al general José María Obando, el 4 de marzo de 1850, en la cual, expresa su indignación por la golpiza de un liberal a manos de conservadores que tenían a su favor un juez letrado:

Hoy ha sido aporreado un hombre patriota, un liberal por gente del partido conservador y tenido a que tienen el juez letrado de ellos, un pícaro una bestia, y cómo es posible, general, que estemos sufriendo nosotros tantas iniquidades, cómo es posible que nosotros trabajemos por el partido cuando salimos perdiendo [...] general, sino encontramos apoyo en el gobierno, 
nosotros, es decir esta población que sus habitantes están al darse de puñaladas por la política, abandonaremos el puerto, porque esto de ir a un presidio o a una reclusión es nada agradable ${ }^{10}$

En este sentido, es importante tener en cuenta, que paralelo a la consolidación de los partidos políticos en Colombia, se consolidaba el periodismo político, el cual dirigía sus pronunciamientos a la defensa o al ataque del partido contradictorio. Al caer el liberalismo en 1855, cuando sube Manuel María Mallarino, Manuel Murillo Toro, se une a otros escritores liberales para fundar el periódico El Tiempo, en el harían firmes aportes ciudadanos de las condiciones intelectuales del mismo Murillo, Camacho Roldan, Miguel y José María Samper, quienes al unísono desarrollarían el criterio liberal por esos años (Arismendi, 1999: 121). En realidad, estos políticos eran excelentes escritores, gracias a la formación educativa que habían adquirido y que por supuesto, habían ligado a la política. En este sentido, el manejo del lenguaje traería beneficios de partido en la medida en que esta competencia lingüística lograra posicionarse en las dinámicas estatales. A través de la política se podría ocupar un puesto en el Estado, que para ese momento simplemente era el mayor empleador,

El único pensamiento de un hombre que sabe leer y escribir es la política, cuando con ello se entienden intrigas, frases y rebeliones. Quién nunca ha trabajado, quién por el contrario durante toda su vida únicamente ha aspirado a obtener un puesto, anhela un puesto con influencia pública, señala a sus enemigos personales como traidores y de vez en cuando

\footnotetext{
${ }^{10}$ Tomado de [Zambrano: 1987]
} 
anhela matar a alguien, a ese se le considera un vivo (Thielmann: 1879: 348 citado en Fischer. Op.cit:54)

Ahora bien esta situación hizo de la administración del Estado, un espacio tanto más atrayente para las demás identidades subordinadas que se inscribían en el espacio social, fenómeno aún más evidente para aquellos grupos sociales bajos, que ante la ausencia de capitales, económicos y culturales hacen del posicionamiento en la política una de sus principales apuestas para solucionar sus condiciones de existencia. Así se puede ver en la descripción que realiza Ernst Röthlisberger, catedrático suizo quien estuvo en Bogotá para el año de 1882:

“Tales fuerzas son el apoyo formal del gobierno [guardia nacional], sobre el que este puede laborar con confianza, a menos que algún soborno o la perspectiva de una mejora de vida y sueldo más alto lleve a los picaros mestizos a echarse en brazos de otro que ofrezca más” (Röthlisberger:1897/1993,p149)

Paralelo a la competencia lingüística del buen decir, se posaba la de escribir de una manera correcta, que le daba al escritor un toque de distinción y de respeto. En efecto, para ser un verdadero político y así distinguirse de los demás grupos sociales era necesario escribir bien, por el contrario, tener un mal uso de la caligrafía era motivo del escarnio y el estigma de ser inculto por no tener disposición estilística y artística. Estas competencias se adquirían en la escuela de primeras letras, donde inculcaban en los niños, la caligrafía. Escribir era un ejercicio que requería una serie de procedimientos técnicos donde contaban: la posición del 
cuerpo (desde los pies hasta la cabeza, pasando obviamente por las manos), la posición del papel (si es el caso) y de la luz. En ese sentido era un problema mecánico, pero también era una cuestión artística por cuanto estaban comprometidas allí las mejores muestras de urbanidad, buenos modales y civilidad. De una elegante, pulcra y fina letra dependía el alto grado de estima que pudiera alcanzar un ciudadano que quisiera llegar a ser respetable. Una buena caligrafía era una excelente carta de presentación en sociedad [Álvarez: 1995: 81] Un ejemplo de lo anterior se encuentra en el relato realizado por Aníbal Galindo, quién describe cómo para llegar a ser un buen político, necesariamente debe poseer una disposición en la escritura

Poco tiempo después de instalada la Administración López de la cual era Secretario de Relaciones Exteriores el doctor Murillo, encontréme un día, por mi desgracia, con él en la plaza de Bolívar, por la acera de los cimientos del Capitolio, bajando él de Palacio para su Secretaría, que estaba en la casa alta de la esquina del camarín de la Concepción, todavía conocida con el nombre de "Casa de las Secretarías," y subiendo yo para mis clases en el Colegio de San Bartolomé. Detúvome el doctor y me dijo: -Sé que usted traduce bastante bien el inglés. Váyase á la Secretaría en sus horas desocupadas, y véase con el Jefe de la Sección 1.o doctor Ortiz (D. José Joaquín), para que me traduzca unos documentos de la cuestión Mackintosh; pero le advierto que no es para darle destino, porque no quiero que se acostumbre usted desde niño á esa vida.

-Con mucho gusto, doctor, le contesté: iré desde mañana entre la una y las tres de la tarde, que son las horas en que no tengo clase. Presentéme al efecto, al día siguiente, con toda puntualidad en la oficina del doctor Ortiz, quien me acomodó una mesita en un rincón de la pieza, separado de todos, con los documentos que debía traducir, un diccionario inglés- 
español, papel y útiles de escribir. Cuatro días haría que estaba yo trabajando en mi traducción, cuando entró un oficial y le dijo al doctor Ortiz:

-El Secretario, que le mande un escribiente.

Paseó el venerable doctor Ortiz la mirada por toda la pieza, y sin saber por qué, pero sobre todo sin derecho para ello, puesto que yo no era empleado, me dijo:

-Galindito, vaya á ver que se le ofrece al Secretario.

Atolondróme yo de tal modo, que no acerté á decirle que mi letra era malísima; habría bastado mostrársela para que me hubiera excusado del servicio.

Pero repito que me atolondré y me fui, sin saber lo que hacía, para el salón de la Secretaria, donde encontré al doctor Murillo, solo, esperando el amanuense que había pedido. Tan pronto como entré acomodóme á la mesa del centro, con papel ministro, magnífico, sin líneas, y principió á dictarme paseándose.

"La fecha.

"A S. E. el señor General Daniel F. O'Leary, Enviado Extraordinario y Ministro Plenipotenciario de Su Majestad Británica, etc., etc., etc." -

Es preciso conocer mi letra, letra de criada, inicua, con la cual nunca he podido escribir una carta á persona por quien se tenga algún respeto, para saber lo que por mí pasaba. Sólo esperando la descarga del ajusticiado sobre el banquillo, podría haber sido más espantosa mi situación, temblando del momento en que el doctor Murillo se acercara á ver lo que yo había escrito, lo que sucedió en el acto de doblar el papel para voltear la hoja. Quedóse el doctor 
Murillo atónito, mirándome como á un salvaje, y despedazando el papel con ambas manos, me dijo:

-Maldita sea su plana; ¿estará usted creyendo que no saber escribir es predisposición de grande hombre? Pues sepa usted que sólo es muestra de mala educación.

Y quien esto decía, bien podía decirlo, porque el doctor Murillo era un excelente calígrafo; poseía una de las más bellas, cursadas y elegantes formas de escritura que puedan envidiarse.

Salí de la pieza adolorido y avergonzado, pero no ofendido con el doctor Murillo, á quien sobraba razón para el regaño. Desgraciadamente no pude enmendar la plana, porque carecía en absoluto de disposición para el dibujo caligráfico.

De acuerdo a lo anterior, la política y una buena educación vendrían de la mano, no solo porque a través del ejercicio de esta se podrían desempeñar cargos estatales, sino en la misma vida política, donde era importante el pronunciamiento y la toma de posición de partido. De otro lado, es importante anotar que esta demostración de la superioridad en el dominio del lenguaje, la cultura y las virtudes morales, cada vez se acercaba más al proyecto cultural basado en el manejo del lenguaje como máxima expresión de la civilización.

En este sentido, se privilegió la representación cultural de la nación dirigida por los letrados. Un ejemplo de lo anterior, se puede encontrar en la celebración oficial del cuarto centenario del descubrimiento de América en 1892 que confirma claramente esta evolución al tiempo que revela la ambigüedad esencial de esta representación predominantemente cultural. [...] La ley de 1890 que prevé la celebración oficial del cuarto centenario del descubrimiento de 
América, dispone la erección de dos estatuas en Bogotá, una de Colón, otra de Isabel la Católica $^{11}$. La celebración, que tiene lugar en el contexto político del plebiscito nacional campaña de consagración de los municipios de Colombia al Sagrado Corazón de Jesús, organizada por la iglesia y la administración Holguín-, es la primera muestra oficial en gran escala, de la sensibilidad hispanista y católica que empieza entonces a reinar en los medios gubernamentales [Martínez 2000::326)

Además de esta representación cultural de la nación que se estaba imponiendo en el ámbito político, el manejo del lenguaje también se estaba disponiendo como un mecanismo simbólico capaz de imponer la arbitrariedad cultural al presentar al lenguaje como atributo que admite la diversidad, pero que al mismo tiempo excluye a las de más identidades por no poseer el talento que solo tienen los letrados. De este modo, cabe mencionar lo que expresa Rufino José Cuervo, acerca de la lengua y los escritores:

"Por maravilla se ofrece hacer mención de la lengua castellana sin que digamos nuestra rica y abundante lengua, nuestra majestuosa y armoniosa lengua, con otros calificativos igualmente encomiásticos; pero si es exacto el concepto que atrás hemos dado a la lengua, lo que realmente tenemos, no es una lengua con esas cualidades, sino escritores que la han comunicado a sus obras. Tales cualidades son como la corrección, la cualidad, la concesión: no existen de suyo en ningún idioma, sino que

\footnotetext{
${ }^{11}$ Además de la poca efectividad en cuanto a la construcción de monumentos se presentaba una postergación del emplazamiento de estas representaciones, el caso más sobresaliente lo constituyó la erección de las estatuas de la reina Isabel y Cristóbal colon dentro de la celebración del IV centenario del descubrimiento de América en 1892, pues bien, estos monumentos fueron emplazados diez y seis años después de haber salido la ley 58 de 1890 que las autorizaba, en parte por la precariedad del presupuesto municipal; de los monumentos aprobados oficialmente para Bogotá hasta 1891 estaba pendiente la construcción de 18 [Tovar: $1997: 147]$
} 
son todas efectos de los talentos, del saber, del gusto y aplicación del que la maneja [Cuervo: 1954, 1654].

En suma, solo los letrados estarían en capacidad de agenciar un proyecto cultural capaz de marcar las pautas de la existencia ciudadana, que nuevamente se afianzaba en los atributos esencializantes, que el régimen identitario de castas le imprimía al lenguaje. Desde fines del siglo XIX, -momento de la historia de Bogotá en que la mayoría de los nacimientos correspondía a los llamados hijos ilegítimos-, el "buen hablar" se asumió como condición para quienes aspiraban a ser considerados gente instruida y bien nacida. En esta labor se destaca el libro Apuntaciones críticas sobre el lenguaje bogotano, de Rufino José Cuervo, publicado en 1872 y reeditado en 1907, así como los trabajos de Miguel Antonio Caro [Zambrano: 2003: 119].

En conclusión, el afán civilizacionista de la identidad dominante presentó una bifurcación, en cuanto al tipo de moral o educación que debían impartir según sus intereses. Por consiguiente el enfrentamiento entre moral civil y moral católica no se hizo esperar; no obstante, el proyecto cultural encabezado por la elite aristocrática se entrometió, gracias a la precariedad del sistema educativo y a las iniciativas privadas, quienes combatieron la idea de civilización Europea, abriendo colegios privados y formando en valores católicos. Por último, es importante entrever que el proyecto cultural promovido por la identidad dominante que enalteció a los letrados, fue tomando fuerza, gracias al manejo del lenguaje que posicionaba a estos hombres como hombres insignes y dignos de seguir. 


\section{Consideraciones finales}

Es importante resaltar que en este análisis se ha privilegiado la eficacia de la lengua como recurso simbólico, donde se ponen en juego los trasuntos de la cultura a partir de estrategias simbólicas movilizadas por diferentes grupos sociales para lograr la cohesión y la legitimación social. En el caso bogotano el uso del más selecto castellano por parte de nuestros ciudadanos, ha sido referido en varias ocasiones, especialmente a la presencia de una tradición de eruditos que desde el siglo XIX se preocuparon por el cultivo de la lengua. No obstante, este calificativo en apariencia sin ninguna sospecha, presenta en la vida cotidiana el efecto estructurador de unas posiciones legitimadas para hablar bien y otras que son excluidas por no hacerlo. Estas formas del buen decir, en este sentido, se corresponderían con unas elites particulares, que a su vez se legitimarían mediante el uso del lenguaje como atributo de distinción. Para cumplir con este objetivo, el presente texto, resultado de esta investigación, presenta en un primer apartado el Estado del Arte, el cual discierne las investigaciones que proyectaron la construcción de la identidad ciudadana en

torno a la lengua. Este apartado en particular, ofrece los insumos teóricos que permitieron vincular los discursos alrededor del uso de la lengua con la construcción de la ciudadanía en Bogotá.

\section{Referencias}

\section{Fuentes primarias}

Carnegie-Williams, R. (1883/1990). Un año en los Andes o aventuras de una lady en Bogotá, Bogotá, Academia de Historia de Bogotá y Tercer Mundo Editores. 
Lisboa, M, 1866/1984, Relación de un viaje a Venezuela, Nueva Granada y Ecuador, Bogotá, Fondo Cultural Cafetero.

Rothlisberger. E. (1897/1993). El dorado. Estampas de viaje y cultura de la Colombia Suramericana. Biblioteca V Centenario. Bogotá. D.C, COLCULTURA,

Cane. M. (1907/1992) Notas de viaje sobre Venezuela y Colombia. Biblioteca V Centenario. Bogotá. D.C. COLCULTURA.

\section{Fuentes secundarias}

Acosta, Carmen. "Literatura vivida, formas de vida y mundos privados: historias del siglo XIX en Colombia. En: historia de la vida privada en Colombia Tomo II los signos de la intimidad el largo siglo XX. Bogotá: Penguin Random House, 2011, 89-113.

Arismendi, Ignacio. Presidentes de Colombia 1810-1990. Bogotá: Editorial Planeta, 1999.

Bourdieu, Pierre. ¿Qué significa hablar? Economía de los intercambios lingüísticos. Madrid: Ediciones Akal. 2001.

Chavarro, César, y Fabián Llano. El héroe, el lujo y la precariedad patrimonio histórico en Bogotá (1880-1950). Bogotá: Editorial Universidad La Gran Colombia, 2010.

Deas, Malcom. “Miguel Antonio Caro y sus amigos: gramática y poder en Colombia”. En Del poder y la gramática y otros ensayos sobre historia politica y literatura colombiana. Bogotá: Tercer mundo editores, 1993, 27-61. 
Fisher, Thomas. "La gente decente en Bogotá Estilo de vida y distinción en el siglo XIX Visto por viajeros extranjeros". Revista colombiana de Antropología volumen 35 (1999): 32-41.

Guillén María Clara. Los colegios mayores San Bartolomé y el Rosario, dos instituciones que sobreviven Revista Credencial Historia. (Bogotá - Colombia). Edición 154 Octubre de 2002.

Gutiérrez, Eugenio. La política instruccionista de los radicales: intento fallido de modernización de Colombia en el siglo XIX (1870-1878). Neiva: Gobernación del Huila, Foncultura, 2000.

Jaramillo, Eduardo. “Artes de la Lectura en la Ciudad del Águila Negra: La Lectura en voz alta y la recitación en Santafé de Bogotá a fines del siglo XIX”. Revista Iberoamericana volumen 14, $\mathrm{n}^{\circ} 2$ (1998): 184-185.

Llano, Fabián. "De escritores despreciables a escritores eximios: el poder de la escritura en Bogotá 1850-1886". Revista Esfera volumen 1, (2011): 21-40.

Llano, Fabian. Caro, Cuervo y la resistencia lingüistica. Construcción de la identidad ciudadana, desde el uso de la lengua. Bogotá (1880-1950). Bogotá: Editorial Universidad La Gran Colombia, 2012.

Martínez, Frédéric. “¿Cómo representar a Colombia? De las exposiciones universales a la exposición del centenario 1851- 1910” En Museo, memoria y nación, misión de los museos nacionales para los ciudadanos del futuro. Bogotá: Editorial Museo Nacional, 2000,23-34.

Mejía, G. (1999) Los años del cambio. Historia urbana de Bogotá (1820- 1910) pontificia Universidad Javeriana Facultad de Ciencias Sociales.

Mejía, Germán. “El idioma de la nación, la experiencia decimonónica colombiana”. Ínsula revista de letras y ciencias humanas, $\mathrm{n}^{\circ} 762$ (2010): 16-20

Mejía, Germán. Los años del cambio. Historia urbana de Bogotá (1820- 1910). Bogotá: Editorial Pontificia Universidad Javeriana, 2008. 
Melo, J. [1991]. La República conservadora. En Colombia Hoy perspectivas hacia el siglo XXI. Siglo XXI editores. Bogotá

Montenegro, Augusto. "La Atenas suramericana. Búsqueda de los orígenes de la denominación dada a Bogotá”. En Revista memoria y sociedad volumen 7, n 14, (2003): 133-143.

Pérgolis, Juan. El deseo de modernidad en la ciudad republicana, Bogotá: editorial Universidad Católica de Colombia, 2013.

Raymond, Williams. Novela y poder en Colombia. Bogotá: Tercer Mundo editores, 1991.

Rincón, Carlos. "Memoria cultural y canon del país de la Atenas Suramericana y el sagrado corazón de Jesús a la lectura de la época de la reproductibilidad digital”. En Literaturas, prácticas críticas y transformación cultural. Bogotá: Editorial Universidad Javeriana, 2008.

Rincón, Carlos. Iconos y mitos culturales en la invención de la nación colombiana. Bogotá: Editorial pontificia Universidad Javeriana, 2014.

Serna, Adrián. Próceres, textos y monumentos: culturas urbanas, discursos escolares y formas de la historia: Bogotá (1938- 1991). Bogotá: Editorial Universidad del bosque, 2001. Documento inédito

Tovar, Bernardo. "Porque los muertos mandan. El imaginario patriótico de la historia colombiana". En Pensar el pasado. Colombia: Archivo general de la nación, 1997.

Vallejo, O. (2010). La construcción literaria de la nación colombiana en: todos somos Colombia Tomo 1. "Unión, rebeldía, integración." 
Von der Walde Uribe, "Erna. Limpia, fija y da esplendor: el letrado y la letra en Colombia a finales del siglo XIX". Revista Iberoamericana volumen. 63, Siglo XIX, fundación y fronteras de la ciudadanía, editado por Susana Rotker, 178-179, Enero-Junio,; 71-83.

Zambrano, Fabio. "Cultura e identidad nacional, una mirada desde la historia" Revista nómadas, $\mathrm{n}^{\circ}$ 1 (1994): 36-45.

Zambrano, Fabio. "De la Atenas suramericana a la Bogotá moderna. La construcción de la cultura ciudadana en Bogotá". Revista de estudios sociales, nº 11 (2002): 9-16.

Zambrano, Fabio. "Documentos sobre sociabilidad en la nueva granada a mediados del siglo XIX". Anuario colombiano de historia social y de la cultura, $\mathrm{n}^{\circ} 15$ (1987): 37-49.

Zambrano, Fabio. La transición al siglo xx: la prensa durante la hegemonía conservadora, en medios y nación, historia de los medios de comunicación en Colombia. Bogotá: Editorial Ministerio de cultura, 2003. 